\title{
LA ALIENACIÓN PARENTAL COMO CAUSA DE VARIACIÓN DE LA TENENCIA
}

PARENTAL ALIENATION AS A CAUSE OF VARIATION OF TENENCE

\author{
William Homer Fernández Espinoza \\ Abogado \\ Universidad de San Martín de Porres \\ william fernandez@usmp.pe
}

Perú

\section{SUMARIO}

- Introducción

- Descripción de la realidad problemática

- Alienación parental

- Protección integral de los derechos del niño

- Derecho del niño a vivir en familia

- Patria potestad

- Tenencia

- Régimen de visitas

- Contrastación y discusión

- Conclusiones

- Recomendaciones

- Referencias

\section{INTRODUCCIÓN}

Este trabajo de investigación estudia la alienación parental y su manifestación en los procesos de tenencia y régimen de visitas como un problema que vulnera los derechos fundamentales de los niños, las niñas y los adolescentes. Estos no se encuentran reconocidos en el ordenamiento jurídico de nuestro país, motivo por el cual, sostenemos, debe ser regulado como una causa de variación de la tenencia.

Para su desarrollo, se realizó un trabajo de campo y se encuestó a 14 magistrados de los juzgados de familia de la Corte Superior de Justicia de Lima ${ }^{1}$. Asimismo, se diseñaron

1 La encuesta fue cursada mediante el Oficio Circular N. 160-2013-SG-CSJLI/PJ emitido por la Secretaría General de la Corte Superior de Justicia de Lima, de fecha 26 de diciembre de 2013. cuadros y gráficos circulares sobre los resultados obtenidos para su contrastación y discusión. También se efectuó el análisis de la doctrina, la legislación y la jurisprudencia nacional e internacional sobre los temas vinculados a esta investigación.

Se presenta la descripción de la realidad problemática y el marco teórico sobre la alienación parental, la patria potestad, los procesos de tenencia y de régimen de visitas, y la protección integral de los derechos del niño (fundamentalmente, del derecho a vivir en familia). De igual manera, se contrastan y discuten los resultados obtenidos en el trabajo de campo. Por último, se ofrecen las conclusiones $\mathrm{y}$ recomendaciones del investigador.

La metodología de investigación es descriptiva y correlacional. Debemos resaltar que este trabajo no pretende agotar el tema de la alienación parental, sino ser una herramienta de ayuda para la solución de este problema.

\section{DESCRIPCIÓN DE LA REALIDAD PROBLEMÁTICA}

Las cifras obtenidas de los censos nacionales de población y vivienda elaboradas por el Instituto Nacional de Estadística e Informática (en adelante INEI) en 1993 y 2007 evidencian el numeroso incremento de separaciones y divorcios tramitados e inscritos en el Perú, especialmente en el departamento de Lima $^{2}$. Esta situación ha devenido en el aumento

2 En el censo de 1993, de la población conformada por 15483 790 peruanos de entre 12 y más años de edad, había 269495 personas separadas y 65654 divorciadas. Recuperado de http://censos.inei.gob.pe/bcoCuadros/CPV93Cuadros.htm [16 de febrero de 2016]. A comparación del censo del 2007, de la población constituida por 20850502 peruanos de entre 12 y más años de edad, 714242 se encontraban separados y 114093 estaban divorciados. Recuperado de http://censos. inei.gob.pe/cpv2007/tabulados [16 de febrero de 2016]. 
considerable del número de procesos de tenencia y de régimen de visitas en los últimos años, registrados principalmente en la Corte Superior de Justicia de Lima ${ }^{3}$.

En los mencionados procesos judiciales se manifiesta un problema al que la doctrina jurídica ha denominado alienación parental. Esta es desarrollada como una conducta obstruccionista y de manipulación del progenitor que tiene la tenencia, aplicada de manera reiterada e injustificada con la finalidad de perjudicar la relación personal, el contacto directo y la comunicación permanente del hijo con el otro progenitor (Fernández, 2015). Para los Jueces de Familia de la Corte Superior de Justicia de Lima, en el $70 \%$ de los procesos de tenencia y/o de régimen de visitas llevados por sus despachos, se determinaron indicadores que manifiestan la existencia de este problema.

No obstante, existe un vacío normativo sobre la regulación jurídica de la alienación parental en nuestro país, que impide que se consigne expresamente en los informes del equipo multidisciplinario, en el dictamen del fiscal de Familia y en las resoluciones emitidas por el juez especializado. Como resultado, se genera un estado de desprotección legal para los niños, las niñas y los adolescentes que participan en estos procesos.

En tal sentido, y por el alto índice de su manifestación y la ausencia de reconocimiento jurídico, sostenemos que la alienación parental es una causa de variación de la tenencia, debido a que este problema vulnera los derechos fundamentales del niño, especialmente aquellos relacionados con su opción de vivir en familia, no ser separados de sus progenitores y mantener relaciones personales, contacto directo y comunicación permanente con ambos padres. Asimismo, se vulneran sus derechos a la integridad personal y a la tutela jurisdiccional efectiva.

Por lo tanto, este trabajo de investigación se desarrolló ante la falta de regulación especializada y por los efectos nocivos que ocasiona este vacío legal, que afecta las

3 Según la información estadística jurisdiccional que se halla en los reportes del Sistema Integrado Judicial - SIJ del Poder Judicial, otorgada por la Unidad de Planificación y Desarrollo de la Corte Superior Justicia de Lima, en el 2011 se iniciaron 813 procesos de tenencia y 349 de régimen de visitas, mientras que en el 2012 se iniciaron 885 y 384, y en el 2013 se registraron 935 y 410 respectivamente. relaciones personales entre los progenitores y sus hijos.

\section{ALIENACIÓN PARENTAL}

Fue propuesta por Richard Gardner ${ }^{4}$ en 1985 como un problema que se manifiesta en los procesos judiciales en que se disputa la custodia de los hijos después de una separación o un divorcio. Este fenómeno está relacionado con un trastorno psicológico conocido como el síndrome de alienación parental (en adelante $\mathrm{SAP}$ ), que se genera en los niños, las niñas y los adolescentes que participan en estos procesos, como consecuencia de la influencia ejercida por uno de sus progenitores (Varsi, 2012).

Gardner sostiene que el SAP es el resultado de la combinación del sistemático adoctrinamiento (lavado de cerebro) de uno de los progenitores y de las propias contribuciones del niño dirigidas a la denigración del padre o de la madre víctima de alienación (citado por Torrealba, 2011).

Por su parte, José Aguilar Cuenca ${ }^{5}$ (2006, p. 23) señala que este síndrome es caracterizado por el conjunto de síntomas que resultan del proceso por el cual un progenitor transforma la conciencia de sus hijos mediante distintas estrategias con el objetivo de impedir, obstaculizar o destruir sus vínculos con el otro progenitor.

En tanto, para Manuel Bermúdez Tapia ${ }^{6}(2009$, pp. 49-50), el SAP es una patología nueva que se analiza en el ámbito de las relaciones conflictivas entre los progenitores, provocando en el hijo una conducta de rechazo sobre un progenitor en particular, sin una justificación objetiva.

En 1999 el Tribunal de Familia de Nueva York, en Estados Unidos, fue el primero en debatir profundamente respecto al SAP en un proceso de custodia. Se señaló que la teoría resultaba controvertida por no figurar en el DSM-IV ${ }^{7}$ o

4 Profesor clínico de psiquiatría en la División Psiquiátrica Infantil de la Universidad de Columbia. En 1985 propone la definición de la alienación parental en su libro The Boys as Girls Book about Divorce.

5 Licenciado en Psicología por la Universidad de Granada, España; especialista en Psicología jurídica y de los primeros en España en tratar el tema de la alienación parental.

6 Abogado. Magíster y doctor en Derecho por la Universidad Nacional Mayor de San Marcos. Profesor universitario y especialista en Derecho de familia.

7 Manual de diagnóstico y estadísticos de los trastornos mentales de la Asociación Estadounidense de Psiquiatria. 
en el CIE- $10^{8}$, y no ser un término aprobado por la Sociedad Americana de Psiquiatría. Sin embargo, el tribunal destacó que no se debatió sobre el SAP como una teoría, sino más bien se discutió si se había indispuesto a los niños en perjuicio del progenitor que no ejerce la custodia (Campana, 2006).

En este caso, tres peritos testificaron que los hijos habían sido alienados de manera insana por uno de los progenitores, lo que generó que el tribunal concediera la custodia exclusiva al progenitor que era víctima de alienación y suspendió las visitas al progenitor alienante. La sentencia no se basó en el SAP, pero sí en la ley aplicable que exhorta al progenitor que ejerce la custodia a fomentar y asegurar la relación de los hijos con el otro que no la ejerce (ibid.).

La alienación parental es definida por Douglas Darnall ${ }^{9}$ como cualquier constelación de comportamientos, sean conscientes o inconscientes, que provocan una perturbación en la relación del niño con uno de sus progenitores (citado por Torrealba, op. cit., p. 31).

De otro lado, Lucía Rodríguez Quintero ${ }^{10}$ (2011, p. 53) califica este problema como aquella conducta llevada a cabo por el padre o la madre que conserva bajo su cuidado al hijo y realiza actos de manipulación con la finalidad de que el niño odie, tema o rechace injustificadamente al progenitor que no tiene la custodia legal.

Para Patricia Beltrán Pacheco ${ }^{11}$ (2004, p. 90), la alienación parental es el proceso a través del cual el progenitor que ejerce la tenencia del hijo programa o condiciona la conducta de este para que sienta recelo, temor o cólera hacia el progenitor que no convive con el niño.

Asimismo, Álex Plácido Vilcachagua ${ }^{12}$ (2011, pp. 19-20) manifiesta que se trata de un proceso

8 Clasificación estadística internacional de enfermedades y problemas relacionados con la salud, recomendada por la Organización Mundial de la Salud.

$9 \mathrm{El}$ autor aporta al estudio de la alienación parental a través de sus libros Divorce Casualties: Protecting your children from parental alienation, de 1998, y Divorce Casualties: Understanding parental alienation, de 2008.

10 Licenciada en Derecho por la Universidad Nacional Autónoma de México y subdirectora del programa sobre Asuntos de la familia, niñez, personas adultas mayores y discapacidad de la Comisión Nacional de los Derechos Humanos de México.

11 Magistrada de la Corte Superior de Justicia de Lima.

12 Abogado por la Universidad de Lima y Magister en Derecho Constitucional por la Pontificia Universidad Católica del Perú. Profesor universitario y especialista en Derecho de la Familia. destinado a romper el vínculo de los hijos con uno de sus padres a través de estrategias desquiciantes que realiza el progenitor, que orienta al rechazo en contra del otro, quien no ha mostrado un comportamiento que pudiera justificar esta campaña de vilipendio.

Lucía Rodríguez agrega que esta conducta tiene como consecuencia que las visitas y convivencias que tendrían que llevarse de manera regular, en las fechas y horarios acordados por las partes (o, en su defecto, establecidos por el juez que conoce del caso), enfrentan toda clase de obstáculos por quien aliena o manipula, que van desde el chantaje, propiciar la culpa, la incomodidad o la pérdida de aprecio del hijo o hija hacia el otro progenitor (op. cit., p. 53).

Por su parte, la especialista Nuria Gonzales $\operatorname{Martín}^{13}$ (2011, pp. 16-17) señala que el denominador de este problema es la utilización del hijo como medio o herramienta para castigar al otro progenitor, ya sean por las causas que originaron la separación o el divorcio, hasta incluso como consecuencia de la falta de pago de los alimentos, la sustracción del hijo, entre otros. Tal situación impide el ejercicio conjunto de la patria potestad y, con el transcurso del tiempo, genera la ruptura del vínculo familiar.

Según Douglas Darnall, la alienación parental se manifiesta a través de una serie de tácticas utilizadas por los progenitores que ejercen estos actos de alienación. Están las siguientes:

1. Entregar abiertamente información a los hijos sobre temas particulares de la separación o el divorcio y otros que no les incumben, y que por su edad no logran comprender. Con ello, se intenta manipular la declaración del niño cuando este manifieste su opinión en los tribunales;

2. Incumplir las órdenes dictadas por el tribunal o incluso las acordadas por los mismos padres. Asimismo, mantener una conducta procesal maliciosa al presentar excesiva documentación que alargue innecesariamente su ejecución, con el propósito de afectar el derecho a la relación directa y regular del niño con el padre víctima de alienación;

13 Doctora en Derecho e investigadora titular en el Instituto de Investigaciones Jurídicas de la Universidad Nacional Autónoma de México. 
3. Condicionar al hijo a través de conductas o comentarios alienantes como «si te vas a vivir con tu madre, ya no te quiero ver más» para generar un distanciamiento entre el progenitor víctima de alienación parental y el niño;

4. Acosar de manera reiterada al otro progenitor a través de amenazas, apariciones inesperadas a la casa familiar, excesivas llamadas telefónicas, entre otros, con la finalidad de conseguir el poder sobre su persona;

5. Utilizar al niño como espía para reunir información sobre el otro progenitor, generándole deslealtad, que mienta y que viole su confianza con el padre víctima de alienación parental;

6. Realizar de manera reiterada comentarios peyorativos y comparaciones sobre el otro progenitor, hasta acusarlo gravemente de actos inexistentes;

7. Perturbar las visitas e impedir que el progenitor víctima de alienación realice actividades o mantenga acceso con su hijo (citado por Torrealba, op. cit., pp.71-78).

De acuerdo con lo expuesto, Enrique Varsi Rospigliosi ${ }^{14}$ y María Paz Sáenz ${ }^{15}$ aseguran en su libro Diálogo con la jurisprudencia que el método más perverso y exitoso para excluir de la vida del niño al progenitor no conviviente son las falsas denuncias. Este medio produce varios efectos: Por un lado, genera una actuación jurisdiccional $\mathrm{y} / \mathrm{o}$ preventiva innecesaria, compromete penalmente al progenitor no conviviente, quien deberá dar explicaciones de actos inexistentes y soportar el clásico estado de sospecha; y, por otro lado, daña psicológicamente al niño (2012, p. 106).

A todo esto, Richard Gardner resalta que no se configura la alienación parental cuando existe realmente un caso genuino de abuso sexual, negligencia parental y/o causa justificada para la separación del niño con cualquiera de sus padres, o generar en el hijo un rechazo contra uno de sus progenitores (citado por Bolaños, 2002, pp. 33-34).

14 Abogado por la Universidad de Lima. Magíster y Doctor en Derecho por la Universidad Nacional Mayor de San Marcos. Profesor universitario y especialista en Derecho de familia. 15 Psicóloga clínica especialista en niños y adolescentes.

\section{PROTECCIÓN INTEGRAL DE LOS DERECHOS DEL NIÑO}

La doctrina de la protección integral de los derechos del niño es una nueva concepción que se construye a través de diversos instrumentos específicos, regionales y universales de protección de los derechos humanos, que representan la expresión de acuerdos e intenciones de la comunidad internacional en esta materia. La creación de nuevos estándares en relación con la condición jurídica de la infancia reconoce al niño como un sujeto pleno de derechos (Beloff, 2004 pp. 31-33).

Este paradigma sustituye a la antigua Doctrina de la Situación Irregular, cuyos principios inspiraron a todas las legislaciones de menores hasta antes del siglo XX; legitimaba las acciones judiciales indiscriminadas en contra de los niños y los adolescentes, criminalizando la pobreza y la situación de abandono en la que se encontraban, y con ello se privilegiaba su institucionalización y se centralizaba el poder de decisión en el juez de menores (García Méndez, 2004, pp. 6-7).

Esta protección integral surge no solo a partir de la Convención sobre los Derechos del Niño ${ }^{16}$ (en adelante, la Convención), sino que es la culminación de todo un proceso progresivo de reconocimiento y protección de los derechos de los niños, que se ha desarrollado en el último siglo (Cillero, 1998, p. 79).

La Convención es uno de los tratados de derechos humanos que ha tenido mayor aprobación y consenso en el mundo ${ }^{17}$. Implica la aceptación de que los niños son las personas más vulnerables en el contexto de violaciones de derechos humanos y que, por lo tanto, requieren de una protección específica (Beloff, op. cit., p. 3).

La Declaración de los Derechos del Niño de $1959^{18}$, que era una formulación de principios

$16 \mathrm{El}$ proyecto de la convención fue presentado por el gobierno de Polonia el 13 de febrero de 1978 y apoyado por países como Austria, Bulgaria, Colombia, Jordania, Senegal y Siria. Fue creado el 20 de noviembre de 1989; adoptado, abierto a la firma y ratificado por la Asamblea General de las Naciones Unidas en su resolución 44/25, entrando en vigor el 2 de septiembre de 1990, de conformidad con su artículo 49. ․ Recuperado de http://www2.ohchr.org/spanish/law/ crc.htm [20 de noviembre de 2015].

17 A octubre del 2015, un total de 196 países se convirtieron en Estados parte de la Convención. Solo Estados Unidos no ha ratificado este acuerdo. Recuperado de http://www.un.org/ spanish/News/story.asp?NewsID=33493\#.VvhjfOLhDIU [25 de marzo de 2016].

18 Adoptada por la Asamblea General de las Naciones Unidas el 20 de noviembre de 1959. 
que proponía el mundo de la posguerra para el trato a los niños, la Convención es un acuerdo respecto del estándar mínimo de tratamiento de la infancia que toda la comunidad internacional estaba obligada a respetar, de modo que el país podía ser responsabilizado y sancionado internacionalmente por su incumplimiento (ibid., p. 12). Esta se ha ocupado en desarrollar en diversas normas al niño ${ }^{19}$ como un sujeto de derecho, en sentido pleno, y no como una persona incapaz, representada así por los adultos. Es así que el niño recibe una amplia gama de derechos y libertades para su protección especial (Baratta, 2007, pp. 20-21).

En la medida en que desarrolla sus capacidades y de acuerdo con su edad, el niño toma control sobre ámbitos competenciales de representación o sustitución delegados a sus padres o al Estado, es decir, adquiere una autonomía progresiva para el ejercicio de sus derechos (Laino, 2012, p. 22).

En consecuencia, se reconoce al niño como titular de todos los derechos inherentes a todas las personas, más derechos específicos por encontrarse en un periodo de crecimiento. No obstante, estos derechos le son limitados por diversas razones, como su falta de madurez, capacidad para formar un juicio propio, su desarrollo emocional o su Interés Superior. A esto se suma que, por la evolución de sus facultades, va adquiriendo la autonomía para el ejercicio de aquellos derechos (Beloff, op. cit. p. 14).

Por otro lado, el Interés Superior del Niño es el principio rector que consagra la base del estatuto del niño como un sujeto de derechos. Es de consideración primordial su atención por parte de las instituciones públicas o privadas de bienestar social, los órganos legislativos, las autoridades judiciales y administrativas del Estado en la actuación y ejecución de todas las medidas que conciernen y afecten a los niños (Cardona, 2012, p. 51).

El concepto de este principio, cuyo origen surge del derecho común, significa esencialmente que cuando se presenta algún tipo de conflicto de interés entre un niño y otra persona, prevalecen los intereses del niño sobre los de otras personas

19 El término niño está referido a todas las personas menores de dieciocho años sujetas a la jurisdicción de un Estado y bajo ningún tipo de discriminación, conforme a lo establecido en los artículos $1 .^{\circ}$ y $2 .^{\circ}$ de la Convención sobre los Derechos del Niño. o instituciones para favorecer la protección de sus derechos (O’Donnell, 1990, p. 19).

El Comité de los Derechos del Niño, a través de la Observación General N. ${ }^{\circ} 14$ del 2013, señala que el Interés Superior del Niño, comprendido en el artículo $3^{\circ}$, párrafo 1 , de la Convención sobre los Derechos del $\mathrm{Niño}^{20}$, tiene como objetivo garantizar el disfrute pleno y efectivo de todos los derechos reconocidos por la Convención y el desarrollo holístico del niño ${ }^{21}$.

En el Perú, lo establecido en la Convención forma parte del derecho nacional ${ }^{22}$ y es de aplicación obligatoria para el Estado peruano. Sus principales atributos y obligaciones están contenidos en el Código de los Niños y Adolescentes (en adelante CNA) ${ }^{23}$.

\section{DERECHO DEL NIÑO A VIVIR EN FAMILIA}

En el artículo $8^{\circ}$ del $\mathrm{CNA}^{24}$ se señala que «el niño, niña y adolescente tienen derecho a vivir, crecer y desarrollarse en el seno de su familia», y a no ser separados de esta «sino por circunstancias especiales definidas en la ley y con la exclusiva finalidad de protegerlos».

20 Artículo 3.

1. En todas las medidas concernientes a los niños que tomen las instituciones públicas o privadas de bienestar social, los tribunales, las autoridades administrativas o los órganos legislativos, una consideración primordial a que se atenderá será el interés superior del niño.

2. Los Estados Partes se comprometen a asegurar al niño la protección y el cuidado necesarios para su bienestar, teniendo en cuenta los derechos y deberes de sus padres, tutores $\mathrm{u}$ otras personas responsables de él ante la ley y, con ese fin, tomarán todas las medidas legislativas y administrativas adecuadas.

3. Los Estados Partes se asegurarán de que las instituciones, servicios y establecimientos encargados del cuidado o la protección de los niños cumplan las normas establecidas por las autoridades competentes, especialmente en materia de seguridad, sanidad, número y competencia de su personal, así como en relación con la existencia de una supervisión adecuada.

21 Recuperado de http://www.unicef.cl/web/informes/ derechos_nino/14.pdf [26 de marzo de 2016].

22 Después de su aprobación y ratificación a través de la Resolución Legislativa N. ${ }^{\circ} 25278$ del 3 de agosto de 1990, y de conformidad con lo establecido en el artículo $55^{\circ}$ y la Cuarta Disposición Final y Transitoria de la Constitución Politica de 1993.

23 Aprobado por la Ley N. 27337 y publicado el 7 de agosto de 2000.

24 Artículo $8 .^{\circ}$ A vivir en una familia

El niño y el adolescente tienen derecho a vivir, crecer y desarrollarse en el seno de su familia.

El niño y el adolescente que carecen de familia natural tienen derecho a crecer en un ambiente familiar adecuado.

El niño y el adolescente no podrán ser separados de su familia sino por circunstancias especiales definidas en la ley y con la exclusiva finalidad de protegerlos.

Los padres deben velar porque sus hijos reciban los cuidados necesarios para su adecuado desarrollo integral. 
Esto sea da en atención a lo dispuesto en el artículo $9^{\circ}$ de la Convención ${ }^{25}$, que establece que los Estados Partes velarán que el niño no sea separado de sus padres, excepto cuando, a reserva de revisión judicial, las autoridades competentes determinen que tal separación es necesaria en el Interés Superior del Niño, de conformidad con la ley y los procedimientos aplicables. También, que se respetará el derecho del niño que esté separado de uno o ambos progenitores «a mantener relaciones personales y contacto directo con ambos padres de modo regular», salvo que ello sea contrario a su interés superior.

El Tribunal Constitucional peruano, a través del expediente N. ${ }^{\circ}$ 01817-2009-PHC/TC del 7 de octubre de 2009, desarrolla que el derecho del niño a vivir en familia y a no ser separado de ella es un derecho fundamental implícito que encuentra sustento en el principio de dignidad de la persona humana y en los derechos a la vida, identidad, integridad personal, libre desarrollo de la personalidad y bienestar. Particularmente, el niño tiene derecho a una familia y a vivir con ella a fin de satisfacer sus necesidades materiales, afectivas y psicológicas ${ }^{26}$.

25 Artículo $9^{\circ}$

1. Los Estados Partes velarán porque el niño no sea separado de sus padres contra la voluntad de estos, excepto cuando, a reserva de revisión judicial, las autoridades competentes determinen, de conformidad con la ley y los procedimientos aplicables, que tal separación es necesaria en el interés superior del niño. Tal determinación puede ser necesaria en casos particulares, por ejemplo, en los casos en que el niño sea objeto de maltrato o descuido por parte de sus padres o cuando estos viven separados y debe adoptarse una decisión acerca del lugar de residencia del niño.

2. En cualquier procedimiento entablado de conformidad con el párrafo 1 del presente artículo, se ofrecerá a todas las partes interesadas la oportunidad de participar en él y de dar a conocer sus opiniones.

3. Los Estados Partes respetarán el derecho del niño que esté separado de uno o de ambos padres a mantener relaciones personales y contacto directo con ambos padres de modo regular, salvo si ello es contrario al interés superior del niño.

4. Cuando esa separación sea resultado de una medida adoptada por un Estado Parte, como la detención, el encarcelamiento, el exilio, la deportación o la muerte (incluido el fallecimiento debido a cualquier causa mientras la persona esté bajo la custodia del Estado) de uno de los padres del niño, o de ambos, o del niño, el Estado Parte proporcionará, cuando se le pida, a los padres, al niño o, si procede, a otro familiar, información básica acerca del paradero del familiar o familiares ausentes, a no ser que ello resultase perjudicial para el bienestar del niño. Los Estados Partes se cerciorarán, además, de que la presentación de tal petición no entrañe por sí misma consecuencias desfavorables para la persona o personas interesadas.

26 'Recuperado de http://www.tc.gob.pe/ jurisprudencia/2009/01817-2009-HC.html [6 de abril de 2015].
La Corte Interamericana de Derechos Humanos, a través de la Opinión Consultiva OC-17/2002 del 2002, resalta que el disfrute mutuo de la convivencia entre padres e hijos constituye un elemento fundamental en la vida de familia. Asegura, además, que aun cuando los padres estén separados de sus hijos, la convivencia familiar debe estar garantizada. El niño debe permanecer en su núcleo familiar, salvo que existan razones determinantes en función del interés superior de aquel para optar por separarlo de su familia. En todo caso, la separación debe ser excepcional y, preferentemente, temporal ${ }^{27}$.

Del mismo modo, la Comisión Interamericana de Derechos Humanos y la Organización de Estados Americanos, a través del informe sobre el derecho del niño y la niña a la familia (2013) señala que, en el ámbito internacional de los derechos humanos, existe el reconocimiento del derecho del niño a vivir en su familia, y a ser cuidado y criado por sus progenitores en el seno de la misma. La responsabilidad primaria por el bienestar del niño y el goce de sus derechos recae en sus progenitores y en los miembros de su familia de origen, independientemente de la composición de esta. A su vez, los progenitores tienen una serie de derechos y responsabilidades en el marco de las relaciones familiares de carácter paterno-filial, que deben ser respetados y garantizados por los $\operatorname{Estados}^{28}$.

\section{PATRIA POTESTAD}

El artículo $418^{\circ 29}$ del Código Civil de 1984 nos da una noción sobre la patria potestad, a la que califican como el deber y el derecho de los padres de cuidar de la persona y de los bienes de sus hijos menores de edad. Ello en concordancia con el segundo y tercer párrafo del artículo $6 .^{\circ 30}$ de la Constitución Política

27 Recuperado de http://www.corteidh.or.cr/docs/opiniones/ seriea_17_esp.pdf [6 de abril de 2015].

28 Recuperado de http://www.oas.org/es/cidh/infancia/ docs/pdf/Informe-derecho-nino-a-familia.pdf [6 de abril de 2015].

29 Artículo $418 .^{\circ}$ Por la Patria Potestad, los padres tienen el deber y el derecho de cuidar de la persona y bienes de sus hijos menores.

30 Artículo $6 .^{\circ}$ La politica nacional de población tiene como objetivo difundir y promover la paternidad y maternidad responsables. Reconoce el derecho de las familias y de las personas a decidir. En tal sentido, el Estado asegura los programas de educación, la información adecuada y el acceso a los medios, que no afecten la vida o la salud.

Es deber y derecho de los padres alimentar, educar y dar seguridad a sus hijos. Los hijos tienen el deber de respetar y asistir a sus padres.

Todos los hijos tienen iguales derechos y deberes. Está 
del Perú, de 1993, que consagra el deber y el derecho de los progenitores con sus hijos, en la alimentación, educación y seguridad con énfasis en la igualdad filiatoria, la promoción y difusión de la paternidad y maternidad responsable.

En otras palabras, puede definirse a esta institución como el conjunto de derechos y deberes para el cuidado y defensa de la integridad de la persona y patrimonio de los hijos (reconocidos ambos progenitores por la ley), hasta que estos adquieran plena capacidad (Varsi, op. cit., p. 294).

La naturaleza jurídica de la patria potestad se explica y fundamenta en el estado por el que atraviesa todo ser humano en la primera etapa de su vida, cuando no se halla en aptitud de proveer a su propia existencia, cautelar sus intereses ni defender sus derechos (Cornejo, 1999, p. 517). Por ello el niño necesita vivir en un ambiente familiar, por ser el entorno idóneo para la protección de sus derechos e intereses y para el desenvolvimiento de su personalidad (Álvarez, 1994, p. 104).

Esta relación jurídica derivada de la filiación que establece en los progenitores autoridad sobre sus hijos, relacionada principalmente con la protección de sus derechos e intereses para su formación y cuidado. Ello es consecuencia del derecho natural y la función social que cumple la familia (Varsi, 2004, p. 240). La patria potestad tiene como finalidad lograr que el niño se desarrolle integralmente bajo el cuidado y crianza de sus progenitores, y se incorpore al seno de la sociedad en óptimas condiciones (Aguilar, 2010, p. 306).

\section{TENENCIA}

Identificada como el derecho y el deber de los progenitores de mantener una convivencia inmediata y relación directa con los hijos para su cuidado y crianza. Asimismo, y de forma recíproca, es el derecho del hijo convivir con el padre que mejores condiciones de vida le ofrezca, para así lograr su desarrollo integral (Varsi, op. cit., p. 304).

En ese sentido, la tenencia es un atributo derivado de la patria potestad, pero no es una facultad exclusiva de los progenitores, sino

prohibida toda mención sobre el estado civil de los padres y sobre la naturaleza de la filiación en los registros civiles y en cualquier otro documento de identidad. una facultad en función de lograr el desarrollo de la personalidad de los hijos. Además, quien goza de la patria potestad, está legitimado para ejercer la tenencia, aunque surjan casos especiales como la separación de cuerpos o divorcio, en que uno de los padres se queda con el cuidado inmediato del hijo (ibid.).

El artículo 81. ${ }^{\circ 31}$ del Código de los Niños y Adolescentes establece que, cuando los progenitores están separados de hecho, la tenencia de los hijos se determina de común acuerdo o, a falta de este, es el juez especializado quien resuelve la disyuntiva ${ }^{32}$, teniendo en cuenta el informe del equipo multidisciplinario $y$ el dictamen fiscal ${ }^{33}$.

En el primer caso, ambos progenitores tienen la voluntad de establecer un acuerdo sobre la tenencia, tomándose en cuenta la opinión de los hijos, con la finalidad de identificar y satisfacer las necesidades de estos. Esta relación trilateral entre el padre, la madre y el hijo permite que todos ellos puedan expresar sus intenciones y deseos de llevar a cabo la tenencia de forma plena y se mantenga una buena relación familiar (ibid. p. 305). En el segundo caso, cuando hay discrepancia sobre la tenencia de los hijos o esta resulta perjudicial para ellos, es el juez especializado quien decidirá conferir la tenencia a uno u otro padre, pudiendo confirmar la continuación de la custodia a quien la tiene o despojársela para entregársela al otro, dictando las medidas necesarias que garanticen su cumplimiento (ibid.).

El artículo $84 .{ }^{034}$ del Código de los Niños y Adolescentes establece los criterios que deberá

31 Artículo $81^{\circ}$ Cuando los padres estén separados de hecho, la tenencia de los niños, niñas o adolescentes se determina de común acuerdo entre ellos y tomando en cuenta el parecer del niño, niña o adolescente. De no existir acuerdo o si este resulta perjudicial para los hijos, la tenencia la resolverá el juez especializado dictando las medidas necesarias para su cumplimiento, pudiendo disponer la tenencia compartida, salvaguardando en todo momento el interés superior del niño, niña o adolescente.

32 Conforme a lo establecido en los artículos $133^{\circ}, 137^{\circ} \mathrm{y}$ $160^{\circ}$ del Código de los Niños y Adolescentes respecto a las atribuciones del juez de familia.

33 Conforme a lo indicado en el segundo párrafo del artículo 87. del Código de los Niños y Adolescentes.

34 Artículo $84 .^{\circ}$ En caso de no existir acuerdo sobre la tenencia, en cualquiera de sus modalidades, el juez resolverá teniendo en cuenta lo siguiente:

a) El hijo deberá permanecer con el progenitor con quien convivió mayor tiempo, siempre que le sea favorable;

b) El hijo menor de tres (3) años permanecerá con la madre; y c) Para el que no obtenga la tenencia o custodia del niño, niña o adolescente, debe señalarse un régimen de visitas. En cualquiera de los supuestos, el juez priorizará el otorgamiento de la tenencia o custodia a quien mejor garantice el derecho del niño, niña o adolescente a mantener contacto con el otro progenitor. 
tomar en cuenta el juez al momento de resolver sobre la tenencia, priorizando sobre todo que, al padre a quien otorgue la custodia, es quien mejor garantice el derecho de sus hijos y permita el contacto con el otro progenitor. Asimismo, el niño deberá permanecer con el progenitor con quien convivió mayor tiempo, siempre que le sea favorable. Cuando sea menor de tres años, este permanecerá con la madre por encontrase en una etapa de lactancia (Mejía y Ureta, 2005, pp. 73-74).

Los criterios fijados en este artículo no son de fatal cumplimiento para el magistrado, sino que constituyen elementos de juicio que deben relacionarse con el interés superior del niño a fin de resolver de la mejor manera la situación del menor de edad y no se prioricen los intereses particulares de los padres (Aguilar, op. cit., p. 342).

El juez deberá resolver el proceso de tenencia después de revisar el informe del equipo multidisciplinario ${ }^{35}$, que trabaja en el Poder Judicial y está comprendido por psicólogos y asistentes sociales. Ellos se encargan de complementar las investigaciones y pruebas necesarias para que el juez determine la tenencia y el régimen de visitas correspondiente ${ }^{36}$ (Mejía y Ureta, op. cit., p. 76). El objetivo de asesoramiento al organismo judicial por parte de este equipo especializado consiste en evaluar la situación del niño o la niña, las relaciones paterno y materno filiales, la idoneidad de establecer y/o modificar regímenes de comunicación, y la valoración de los entornos familiares (Gimeno y Orti, 2011, p. 660).

Del informe del psicólogo se desprende la situación emocional que vive el niño con cada uno de sus progenitores. Asimismo, se evalúa al padre y la madre para determinar cuál de ellos es el más idóneo para mantener bajo su cuidado al hijo. Y del informe de la asistencia social

$35 \mathrm{El}$ artículo $149 .^{\circ}$ del Código de los Niños y Adolescentes establece que:

El Equipo Multidisciplinario estará conformado por médicos, psicólogos y asistentes sociales. Cada Corte Superior de Justicia designará a los profesionales de cada área, los que ejercerán sus funciones en forma obligatoria en cada Juzgado que ejerza competencia en niños y adolescentes.

$36 \mathrm{El}$ artículo $150 .^{\circ}$ del Código de los Niños y Adolescentes establece que:

Artículo $150 .^{\circ}$ Son atribuciones del Equipo Multidisciplinario: a) Emitir los informes solicitados por el juez o el fiscal

b) Hacer el seguimiento de las medidas y emitir dictamen técnico para efectos de la evaluación correspondiente, asi como las recomendaciones para la toma de las medidas pertinentes; y

c) Las demás que señale el presente Código. se brindará la información correspondiente al estado socioeconómico que desenvuelve el niño y el de sus padres (Mejía y Ureta, op. cit., p. 77).

El artículo $138^{\circ}$ del Código de los Niños y Adolescentes establece que el fiscal de Familia tiene por función principal velar por el respeto de los derechos del niño y del adolescente, promoviendo de oficio o a petición de parte las acciones legales correspondientes ${ }^{37}$. Entre sus atribuciones, el fiscal interviene, de oficio y desde la etapa inicial, en todos los procesos judiciales en que participan menores de edad, en resguardo y protección de sus derechos ${ }^{38}$.

37 Artículo $138^{\circ} \mathrm{El}$ fiscal tiene por función primordial velar por el respeto de los derechos y garantías del niño y del adolescente, promoviendo de oficio o a petición de parte las acciones legales, judiciales o extrajudiciales correspondientes.

$38 \mathrm{El}$ artículo $144 .^{\circ}$ del Código de los Niños y Adolescentes establece que compete al fiscal:

a) Conceder la remisión como forma de exclusión del proceso;

b) Intervenir, de oficio y desde la etapa inicial, en toda clase de procedimientos policiales y judiciales en resguardo y protección de los derechos del niño y del adolescente.

Es obligatoria su presencia ante la policía en las declaraciones que se actúen en casos de violencia sexual contra niños o adolescentes, bajo sanción de nulidad y responsabilidad funcional. En este último caso, ordenará la evaluación clínica y psicológica de la víctima por personal profesional especializado y, concluida dicha evaluación, remitirá al Fiscal Provincial Penal de turno un informe, el acta que contiene el interrogatorio de la víctima y los resultados de la evaluación.

Durante la declaración de la víctima, puede participar cualquiera de los padres o la persona que tenga bajo su tutela al menor de edad, siempre que no fueran los denunciados. Si los padres o la persona que tiene bajo su tutela al menor de edad no pudieran participar, podrán designar una persona que los represente;

c) Promover los procedimientos relativos a las infracciones atribuidas a los adolescentes. En este caso, corresponde al fiscal investigar su participación con el propósito de solicitar la medida socioeducativa necesaria para su rehabilitación; d) Promover las acciones de alimentos, si fuere el caso, conforme a lo dispuesto en el presente código y las normas procesales de la materia;

e) Promover la acción civil o administrativa para la protección de los intereses difusos o colectivos de los niños y adolescentes previstos en este Código;

f) Inspeccionar y visitar las entidades públicas y privadas, las organizaciones comunales y las organizaciones sociales de base encargadas de brindar atención integral al niño y adolescente, y verificar el cumplimiento de sus fines;

g) Solicitar el apoyo de la fuerza pública, así como la colaboración de los servicios médicos, educativos y de asistencia pública y privada, en el ejercicio de sus funciones; h) Instaurar procedimientos en los que podrá:

-Ordenar notificaciones para solicitar las declaraciones para el debido esclarecimiento de los hechos. En caso de inconcurrencia del notificado, este podrá ser requerido mediante la intervención de la autoridad policial;

- Solicitar a las autoridades toda clase de información, pericias y documentos que contribuyan al esclarecimiento del hecho investigado;

- Pedir información y documentos a instituciones privadas, con el mismo fin; y

i) Las demás atribuciones que señala la ley.

j) Actuar como conciliador del conflicto en asuntos de familia para propiciar acuerdos entre las partes y lograr la solución consensual al conflicto, siempre y cuando no se hubiere iniciado proceso judicial. No podrá propiciar acuerdos sobre derechos no disponibles, irrenunciables o sobre materias que tengan connotación penal. 
En los procesos de tenencia y de régimen de visitas en que participa el fiscal de Familia (después de actuadas las pruebas y antes de que se expida la sentencia), este debe emitir un dictamen ${ }^{39}$ con los pedidos para la toma de las medidas correspondientes en el proceso, las cuales serán evaluadas por el juez especializado.

En tanto, el artículo $85^{\circ}$ del Código de los Niños y Adolescentes señala que el juez deberá escuchar al niño y tomar en cuenta su opinión en los procesos en que participa, cuando este es adolescente ${ }^{40}$. Esto en concordancia con lo establecido en el artículo $12 .{ }^{\circ 41}$ de la Convención sobre los Derechos del Niño, que establece que, en todos los asuntos que afecten al niño, este podrá expresar libremente su opinión, la que deberá ser tomada en cuenta por la autoridad, en función de su edad y madurez.

Desde el momento en que el niño puede expresarse, tiene derecho a manifestar su propia opinión $\mathrm{y}$, desde que es adolescente, tal opinión debe ser obligatoriamente tomada en cuenta por la autoridad administrativa o judicial que mantenga competencia sobre un proceso en el que estén involucrados menores de edad (Chunga F., Chunga C. y Chunga L., 2012, p. 399).

El Comité de los Derechos del Niño señala que, el hecho de que este sea muy pequeño o se encuentre en una situación vulnerable, no le priva del derecho a expresar su opinión, ni reduce la importancia que debe concederse a sus opiniones al determinar el interés superior (Comité de los Derechos del Niño, 2013, pp. 13-14).

Asimismo, el comité, a través de la Observación General N. ${ }^{\circ} 12$ sobre el derecho del niño a ser escuchado (2009) indica que no se puede escuchar eficazmente a un niño cuando el entorno es intimidatorio, hostil, insensible o inadecuado para su edad. Los procedimientos tienen que ser accesibles y apropiados para los niños. Debe prestarse especial atención al suministro y la transmisión de información adaptada a ellos, la prestación de apoyo adecuado para la defensa de los intereses propios, la debida capacitación

39 Artículo $141^{\circ} \mathrm{El}$ dictamen, en los casos que procede, es fundamentado después de actuadas las pruebas y antes de que se expida sentencia. Los pedidos que formula deben ser motivados y presentados en una sola oportunidad.

40 Conforme al artículo I del Título Preliminar del Código de los Niños y Adolescentes, se considera niño hasta los doce años de edad y adolescente hasta los dieciocho. del personal, el diseño de las salas de tribunal, la vestimenta de los jueces y abogados, y la disponibilidad de pantallas de protección visual y salas de espera separadas (Comité de los Derechos del Niño, 2009, p. 12).

Para dar cumplimiento a lo dispuesto por la ley, el juez debe oír en forma personal y directa al niño en una audiencia que podrá ser solicitada por cualquiera de las partes, el fiscal o incluso ser dispuesta de oficio por el juez especializado. El contacto personal del juez con el niño o adolescente debe efectuarse con mucha prudencia, tacto y sensibilidad, teniendo presente en todo momento que estamos ante un ser en desarrollo al que debemos proteger al extremo (Giménez de Allen, 2010, p. 97).

En estas entrevistas, se oye a los niños manifestar sus opiniones y declaraciones, como con quién viven, con quién desean vivir, con cuál de los padres se llevan mejor, con quién se identifican más, qué estímulos y sanciones reciben, entre otras preguntas. El fin es que el juez tenga un mayor conocimiento sobre las relaciones entre los padres y los hijos para resolver de la mejor manera la situación del niño, en consideración de su interés superior (Jara y Gallegos, 2011, p. 438).

Asimismo, el juez debe valorar la autenticidad de las manifestaciones del niño debido a que muchas veces estas son influenciadas o manipuladas por uno de sus progenitores, por lo que sus opiniones no nacen de ellos mismos sino de terceros, que son los mismos padres o miembros de su entorno. Además, la falta de cumplimiento del derecho del niño a ser oído dentro del proceso judicial debe ser sancionada con la nulidad del mismo (Giménez de Allen, op. cit., pp. 99-101).

\section{RÉGIMEN DE VISITAS}

El régimen de visitas forma parte de la relación jurídica familiar que identifica el derecho y el deber de los progenitores, que no gozan de la tenencia, de mantener un contacto directo e inmediato con sus hijos, cuando no existe una cohabitación permanente entre ellos, con la finalidad de fortalecer las relaciones paternofiliales y lograr el desarrollo integral del niño (Varsi, op. cit., p. 311).

Esta relación no solo implica que el padre visite a su hijo, sino también compartir, supervisar, 
responsabilizarse de manera integral y lograr una adecuada comunicación entre ambos (ibid.). Ello en concordancia con el tercer párrafo del artículo $9 .{ }^{\circ 42}$ de la Convención sobre los Derechos del Niño, que establece su derecho a no ser separado de sus progenitores y a mantener relaciones personales y contacto directo con ellos, salvo que sea contrario a su interés superior.

Asimismo, la privación del derecho de comunicación entre el hijo y sus progenitores solo puede tener lugar por causas muy graves que pongan en peligro la seguridad o salud física o moral de las niñas, niños o adolescentes (Belluscio, 2013, pp. 841-842).

Este trato del hijo con el padre no conviviente obedece a motivos tan humanos y respetables que ni la ruptura del vínculo matrimonial puede ser un obstáculo para que no se establezca. De otro modo, sería contrario al interés del hijo romper aquellos vínculos familiares. No obstante, si esa relación afecta la salud física y moral del niño, es justificable que se deje de mantener dicho contacto (Plácido, 2001, p. 333).

El régimen de visitas puede extenderse, en ciertas circunstancias, a favor de los parientes colaterales hasta el cuarto grado de consanguinidad y segundo de afinidad, e incluso a terceros ${ }^{43}$, cuando el interés superior del Niño así lo justifique (Mejía, 2013, p. 69). De igual manera, los progenitores, el tutor o quien tenga la responsabilidad de tener bajo su cuidado al niño, niña y adolescente, está obligado a permitir el ejercicio de las visitas (Méndez y D' Antonio, 2001, p. 496).

Los artículos $88^{\circ 44}$ y $89^{\circ 45}$ del Código de los Niños y Adolescentes, así como el artículo 422. ${ }^{\circ 4}$ del Código Civil, establecen que los progenitores que no gozan de la tenencia de sus hijos, tienen el derecho de poder visitarlos. Para ello pueden solicitar se les otorgue un régimen de visitas. Así, los que han sido impedidos o limitados de ese derecho, podrán exigir al juez especializado se les conceda uno provisional.
El régimen de visitas puede ser acordado de manera voluntaria por ambos progenitores, inclusive a través de un proceso de conciliación extrajudicial. Asimismo, puede establecerse a través de la sentencia judicial que resuelve los casos de separación de cuerpos, divorcio, nulidad o tenencia. Incluso, el juez tiene la facultad de otorgarlo de oficio ante la falta de solicitud de las partes, en consideración del interés superior del niño (Varsi, op. cit., p. 322).

El incumplimiento del régimen de visitas, establecido judicialmente por parte del progenitor que mantiene la tenencia, dará lugar a los apremios de ley como lo son las multas y, en caso de resistencia, podrá originar la variación de la tenencia (Aguilar, op. cit., p. 345).

\section{CONTRASTACIÓN Y DISCUSIÓN}

La respuesta a la pregunta de la encuesta: ¿Conoce si la jurisprudencia peruana resolvió algún caso de alienación parental?, el 57 \% de los magistrados contestó que sí, mientras que el $43 \%$ respondió que no (vea cuadro 1 y el gráfico 1). Esto demuestra que un gran porcentaje de los jueces encuestados desconoce de la existencia de casuística nacional sobre la alienación parental. Ello pese a que este tema dejó de ser desconocido, debido a que en los últimos años la Corte Suprema de Justicia se pronunció al respecto a través de las Casaciones N. ${ }^{\circ}$ 2067-2010-LIMA, N. ${ }^{\circ}$ 5138-2010-LIMA y N. ${ }^{\circ} 370-2013-I C A$.

En la Casación N. ${ }^{\circ}$ 2067-2010-LIMA, a través del informe del equipo multidisciplinario, se manifestó la existencia de actos de alienación parental realizados por el padre con el propósito de resquebrajar la relación entre la madre y sus hijos. Conforme se señala en la sentencia, el padre imputaba a la madre actos de violencia física en agravio de los niños, abandono injustificado del hogar y conductas inadecuadas; sin embargo, tales acusaciones no fueron probadas ${ }^{47}$.

\begin{tabular}{|c|c|c|c|c|}
\hline \multicolumn{5}{|l|}{ Cuadro 1} \\
\hline \multirow[b]{2}{*}{ PREGUNTA } & \multirow[b]{2}{*}{ SÍ } & \multirow[b]{2}{*}{ NO } & \multicolumn{2}{|c|}{ ESTADÍSTICA } \\
\hline & & & Sí & NO \\
\hline $\begin{array}{l}\text { ¿Conoce si la jurisprudencia peruana resolvió algún caso } \\
\text { de alienación parental? }\end{array}$ & 8 & 6 & $57 \%$ & $43 \%$ \\
\hline
\end{tabular}

Fuente: Elaboración propia 


\section{Gráfico 1}

¿Conoce si la jurisprudencia peruana resolvió algún caso de alienación parental?

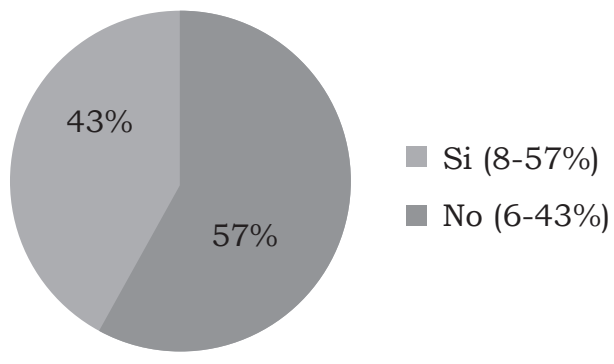

En este caso, la prueba de la existencia de actos de alienación parental no fue determinante debido a que la Corte preponderó el derecho a la integridad física y psicológica de los hijos ante la evidencia de abuso sexual que sufrían por parte del padre ${ }^{48}$. Por ello, se declaró infundado el recurso de casación, confirmando la sentencia que declaraba injustificada la demanda de tenencia interpuesta por el padre, y fundada la de la madre.

En tanto, en la Casación N. ${ }^{\circ}$ 5138-2010-LIMA, a través del informe del equipo multidisciplinario, se manifestó la existencia de actos de alienación parental realizados por la madre, debido a la conducta obstructiva que mantenía cuando ostentaba la tenencia provisional. Ello porque no prestaba colaboración para que la relación entre el padre y sus hijas se efectivice, ni contribuía o garantizaba el vínculo paterno-filial a través de las visitas ${ }^{49}$.

La Corte argumentó su decisión en la conducta que mantiene la madre, quien incumplió con dicho mandato pese a que la sentencia de primera instancia le ordenaba entregar a las niñas al padre. Asimismo, concluyó que estos actos realizados por su parte la desmerecían para el ejercicio cabal de una posible tenencia a su favor ${ }^{50}$. En este caso, la Corte Suprema declaró infundado el recurso de casación interpuesto por la madre y confirmó la tenencia a favor del padre.
Por último, en la Casación N. ${ }^{\circ}$ 370-2013-ICA se evidenció, a través del examen psicológico efectuado al niño, que el padre practicaba actos de alienación parental. Ello debido a que se apreció que el hijo manifestaba una animadversión hacia su madre a través de actitudes que advertían un adiestramiento previo, y en su opinión cuando este expresaba su deseo de vivir con su padre ${ }^{51}$. La Corte fundamentó su decisión en la conducta que realizaba el padre al influir negativamente en el hijo con el propósito de impedir y obstaculizar la relación del niño y su madre ${ }^{52}$. Finalmente, se declaró improcedente el recurso de casación, con lo que se reafirmó la tenencia a favor de la madre.

Del análisis de estas sentencias, se evidencia que la alienación parental es determinada en los informes emitidos por los psicólogos y los asistentes sociales pertenecientes al equipo multidisciplinario, pero a través de indicadores que demuestran la existencia de conductas obstruccionistas y de manipulación realizadas por el progenitor que tiene la tenencia, ya que no es consignada de manera expresa, justamente por su falta de regulación jurídica. Ello a excepción de la casuística antes mencionada, en el que este problema sí es mencionado explícitamente, pero no se resolvió sobre la base de la alienación parental.

Luego de la pregunta de la encuesta: ¿El equipo multidisciplinario determinó en algunos de sus informes la existencia de alienación parental en los procesos de tenencia y/o de régimen de visitas llevados por su despacho?, el $71 \%$ de los magistrados respondió que sí, mientras que el $29 \%$ contestó que no (vea el cuadro 2 y el gráfico 2). Esto demuestra que la mayoría de jueces encuestados conocieron casos en lo que se manifestaron actos de alienación parental. No obstante, la ausencia de reconocimiento jurídico de este problema, como se acotó anteriormente, genera que esta situación no sea tomada en consideración por los magistrados y demás operadores jurisdiccionales, y, peor aún, no sea reconocido como un factor determinante para establecer la tenencia y/o el régimen de visitas, o su variación.

Cuadro 2
\begin{tabular}{|c|c|c|c|c|}
\hline \multicolumn{1}{|c|}{ PREGUNTA } & SÍ & NO & SÍ & NO \\
\hline $\begin{array}{l}\text { ¿El equipo multidisciplinario determinó en algunos de sus } \\
\text { informes la existencia de alienación parental en los procesos de } \\
\text { tenencia y/o de régimen de visitas llevados por su despacho? }\end{array}$ & 10 & 4 & $71 \%$ & $29 \%$ \\
\hline
\end{tabular}

Fuente: Elaboración propia. 


\section{Gráfico 2}

¿El equipo multidisciplinario determinó en algunos de sus informes la existencia de alienación parental en los procesos de tenencia y/o de régimen de visitas llevados por su despacho?

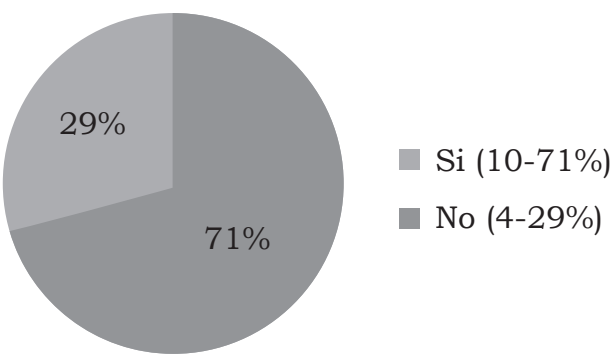

En ese sentido, nos preguntamos: ¿Qué problemas genera la existencia de un vacío normativo sobre la regulación jurídica de la alienación parental en nuestro país?

Al respecto, debemos recordar que, como lo señala Lucía Rodríguez (Op. cit., pp. 53-54), en los casos en que se manifiesta la alienación parental, se tiene como consecuencia que las visitas y convivencias que tendrían que desarrollarse de manera regular, en las fechas y horarios acordados por los padres (o en su defecto establecidos por el juez que conoce del caso) enfrenta toda clase de obstáculos por quien aliena o manipula, que sin causa real o justiciada impide las relaciones personales del hijo con el otro progenitor.

En tanto, Enrique Varsi (op. cit., p. 311) sostiene que los progenitores deben mantener un contacto directo e inmediato con sus hijos cuando no existe una cohabitación permanente entre ellos. Ello con la finalidad de fortalecer las relaciones paterno-filiales, mantener una adecuada comunicación entre ambos y lograr el desarrollo integral del niño.

Asimismo, en opinión de Alex Plácido (2011, p. 22), el disfrute de la compañía de cada uno de los padres con el hijo constituye un elemento fundamental de la vida familiar, aun cuando la relación de los padres se haya roto. Por ello, las medidas internas que obstaculicen ese disfrute constituyen una violación del derecho del niño a mantener relaciones personales y contacto directo con ambos padres, como ocurre en los casos de alienación parental.
Lo anterior se desarrolla según lo indicado en el artículo $8 .^{\circ}$ del Código de los Niños y Adolescentes, en concordancia con lo dispuesto en el artículo 9..$^{\circ}$ de la Convención sobre los Derechos del Niño, que establece el derecho del niño a vivir en familia, a no ser separado de sus progenitores sino por circunstancias especiales definidas en la ley y con la exclusiva finalidad de protegerlos, y a mantener relaciones personales y contacto directo con ambos padres, salvo que esta situación sea contraria a su interés superior.

Como observamos, la alienación parental es una conducta injustificada de obstrucción y de manipulación que perjudica las relaciones personales y la convivencia del hijo con sus padres. Ante la existencia de un vacío normativo sobre la regulación de este problema, el niño se encuentra en un estado de desprotección legal, debido a que, como nos referimos párrafos atrás, la alienación parental no es tomada en consideración por el juez especializado, y tampoco por el fiscal de Familia y los miembros del equipo multidisciplinario. Tal situación genera que, en los procesos donde se manifiesta, no se trate debidamente el problema ni se tomen las medidas de protección necesarias para restituir los derechos vulnerados del hijo, especialmente aquellos relacionados a vivir en familia, así como su derecho a la integridad personal y al ejercicio de la tutela jurisdiccional efectiva.

Frente a esta situación de vulneración de sus derechos, sostenemos que las medidas de protección idóneas en estos casos serán primordialmente aquellas que permitan reencausar los lazos afectivos del hijo con ambos padres.

Cuando en la encuesta se preguntó: ¿Considera que la terapia psicológica familiar es la medida de protección más adecuada para los niños, niñas y adolescentes víctimas de alienación parental?, el $100 \%$ de los jueces contestó que sí (vea el cuadro 3 y el gráfico 3). Esto demuestra que la totalidad de los magistrados encuestados consideran que la terapia psicológica familiar es la medida de protección más adecuada para los niños, niñas y adolescentes víctimas de alienación parental, debido a que esta medida permitirá reformular positivamente la relación con el padre y la madre. 


\section{Cuadro 3}

\begin{tabular}{|c|c|c|c|c|}
\hline \multirow[b]{2}{*}{ PREGUNTA } & \multirow[b]{2}{*}{ SÍ } & \multirow[b]{2}{*}{ NO } & \multicolumn{2}{|c|}{ ESTADÍSTICA } \\
\hline & & & SÍ & NO \\
\hline $\begin{array}{l}\text { ¿Considera que la terapia psicológica familiar es la } \\
\text { medida de protección más adecuada para los niños, niñas } \\
\text { y adolescentes víctimas de alienación parental? }\end{array}$ & 14 & 0 & $100 \%$ & $0 \%$ \\
\hline
\end{tabular}

Fuente: Elaboración propia

\section{Gráfico 3}

¿Considera que la terapia psicológica familiar es la medida de protección más adecuada para los niños, niñas y adolescentes víctimas de alienación parental?

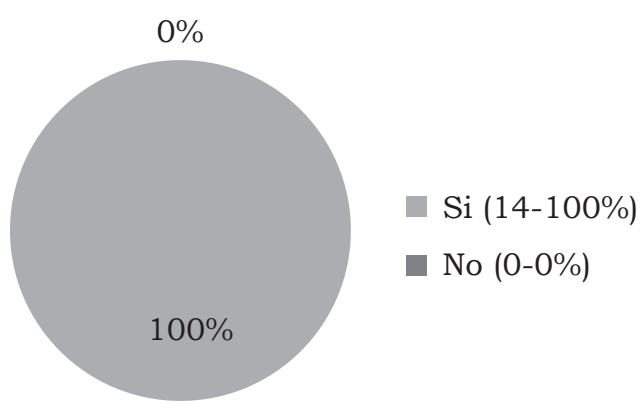

Al respecto, y siguiendo la propuesta de Richard Gardner, Ignacio Bolaños ${ }^{53}$ señala que se plantea la necesidad de que el juzgado ordene un tratamiento psicológico para la familia y que el terapeuta tenga un contacto directo con el juez a fin de proveerle la información necesaria sobre el caso. Asimismo, se requiere una postura judicial clara respecto a las posibles sanciones, en el supuesto de que el progenitor alienante boicotee el proceso (Bolaños, op. cit., p. 91). Al respecto, consideramos que el juez especializado deberá promover sus facultades coercitivas, pudiendo imponer multas compulsiva y progresivamente a las partes a fin de que se cumplan sus mandatos con arreglo al contenido de su decisión. Ello ante el incumplimiento de lo ordenado por el juzgado y aplicando lo dispuesto en el artículo $53^{\circ}$ del Código Procesal Civil. Sin embargo, si persistieran las conductas de alienación parental, nos preguntamos: ¿Una solución sería separar al niño víctima de alienación del progenitor alienante? Recordemos que el Comité de los Derechos del Niño, a través de la Observación General N. ${ }^{\circ}$ 14, señala que la prevención de la separación familiar y preservación de su unidad son elementos importantes del régimen de protección del niño, y se basan en el derecho recogido en el artículo $9^{\circ}$ de la Convención. De igual manera, dada la gravedad de los efectos en el niño al ser separado de sus padres, dicha medida solo debería aplicarse como último recurso, por ejemplo, cuando el niño esté en peligro de sufrir un daño inminente o cuando sea necesario por otro motivo. La separación no debería llevarse a cabo si se puede proteger al niño de un modo que se inmiscuya menos en la familia (Comité de los Derechos del Niño, 2013, pp. 14-15).

Asimismo, la Corte Interamericana de Derechos Humanos, a través de la Opinión Consultiva OC-17/2002, resalta que el niño debe permanecer en su núcleo familiar, salvo que existan razones determinantes, en función del interés superior de aquel, para optar por separarlo de su familia. En todo caso, la separación debe ser excepcional $y$, preferentemente, temporal.

Acerca de la pregunta de la encuesta: ¿Considera que el niño, niña o adolescente víctima de alienación debe ser separado del progenitor alienante?, el $86 \%$ de los jueces contestaron afirmativamente (vea el cuadro 4 y el gráfico 4). Esto demuestra que la mayoría de los magistrados encuestados considera que el niño o adolescente víctima de alienación parental sí debe ser separado del progenitor alienante. Además, los jueces resaltan que esta separación debe aplicarse de manera progresiva a fin de que no se continúe perjudicando la integridad del hijo, salvo que dada la gravedad del caso, esta sea de manera inmediata, según lo señale el informe del equipo multidisciplinario. 


\begin{tabular}{|c|c|c|c|c|}
\hline \multicolumn{1}{c|}{ Cuadro 4 } & \multicolumn{2}{c|}{ ESTADÍSTICA } \\
\hline \multicolumn{1}{c|}{ PREGUNTA } & SÍ & NO & SÍ & NO \\
\hline $\begin{array}{l}\text { ¿Considera que el niño, niña o adolescente víctima de } \\
\text { alienación debe ser separado del progenitor alienante? }\end{array}$ & 12 & 2 & $86 \%$ & $14 \%$ \\
\hline
\end{tabular}

\section{Gráfico 4}

¿Considera que el niño, niña o adolescente víctima de alienación debe ser separado del progenitor alienante?

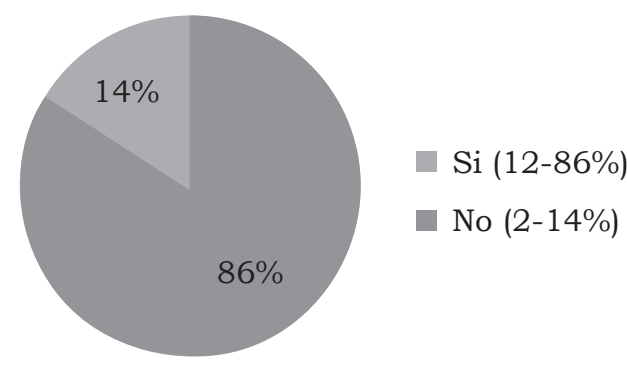

Fuente: Elaboración propia

Siguiendo esta línea, se preguntó en la encuesta: ¿Considera que la alienación parental es una causa que genera la variación de la tenencia? El $79 \%$ de los jueces respondió que sí, frente al $21 \%$ que dijo que no (vea el cuadro 5 y el gráfico 5). Esto demuestra que la mayoría de los magistrados encuestados considera que la alienación parental sí es una causa de variación de la tenencia.

El Código de los Niños y Adolescentes desarrolla que la variación de la tenencia es una medida que busca proteger los derechos del hijo. El juez especializado es quien determina, por decisión motivada y bajo la asesoría de los miembros del equipo multidisciplinario y previo dictamen del fiscal de Familia, que esta se efectué de manera progresiva para no producir algún daño o trastorno en el niño. Sin embargo, cuando peligre la integridad del menor de edad, esta se efectuará de manera inmediata ${ }^{54}$.

Cuando persistan las conductas alienantes, es necesario que el niño, niña o adolescente víctima de alienación sea separado del progenitor alienante, pudiéndose variar la tenencia a favor del otro progenitor, según cada caso y en atención al interés superior del niño.

\begin{tabular}{|c|c|c|c|c|}
\hline \multicolumn{5}{|l|}{ Cuadro 5} \\
\hline \multirow[b]{2}{*}{$\begin{array}{r}\text { PREGUNTA } \\
\end{array}$} & \multirow[b]{2}{*}{ SÍ } & \multirow[b]{2}{*}{ NO } & \multicolumn{2}{|c|}{ ESTADÍSTICA } \\
\hline & & & SÍ & NO \\
\hline $\begin{array}{l}\text { ¿Considera que la alienación parental es una causa que } \\
\text { genera la variación de la tenencia? }\end{array}$ & 11 & 3 & $79 \%$ & $21 \%$ \\
\hline
\end{tabular}

Fuente: Elaboración propia

\section{Gráfico 5}

¿Considera que la alienación parental es una causa que genera la variación de la tenencia?

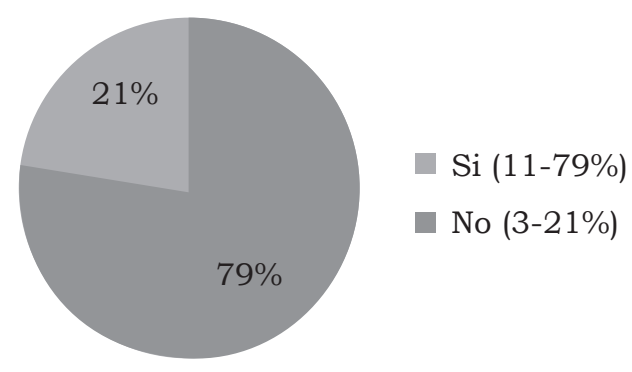

Del análisis de las respuestas y lo desarrollado, se evidencia que las medidas de protección que se deberán otorgar para restituir los derechos vulnerados de los niños, niñas y adolescentes víctimas de alienación parental son los siguientes: primero, ordenar una terapia psicológica familiar a fin de restablecer la relaciones con el padre y la madre; segundo, imponer el pago de multas compulsiva y progresivamente a las partes que incumplan con los mandatos judiciales; y, por último, disponer la variación de la tenencia. 
Cuando se preguntó en la encuesta: ¿Se debe regular la alienación parental en el ordenamiento jurídico peruano?, el $86 \%$ de los jueces respondió que sí, mientras que el $14 \%$ dijo que no (vea el cuadro 6 y el gráfico 6). Esto demuestra que la mayoría de los magistrados encuestados considera necesaria la regulación de la alienación parental en nuestro ordenamiento jurídico.
Además, los jueces sostienen que debe incorporarse la alienación parental en el Código de los Niños y Adolescentes como una causa que genera la variación de la tenencia a fin de que se aplique esta medida de protección en los casos que lo ameriten, y en consideración de otorgar primero aquella medida que permita reencausar los lazos familiares entre el hijo y sus padres, y evitar así su separación.

\begin{tabular}{l}
\hline \multicolumn{1}{|c|}{ Cuadro 6 } \\
\begin{tabular}{|l|c|c|c|c|}
\hline \multicolumn{1}{|c|}{ PREGUNTA } & SÍ & NO & SÍ & NO \\
\hline $\begin{array}{l}\text { ¿Se debe regular la alienación parental en el ordenamiento } \\
\text { jurídico peruano? }\end{array}$ & 12 & 2 & $86 \%$ & $14 \%$ \\
\hline
\end{tabular}
\end{tabular}

Fuente: Elaboración propia

\section{Gráfico 6}

¿Se debe regular la alienación parental en el ordenamiento jurídico peruano?

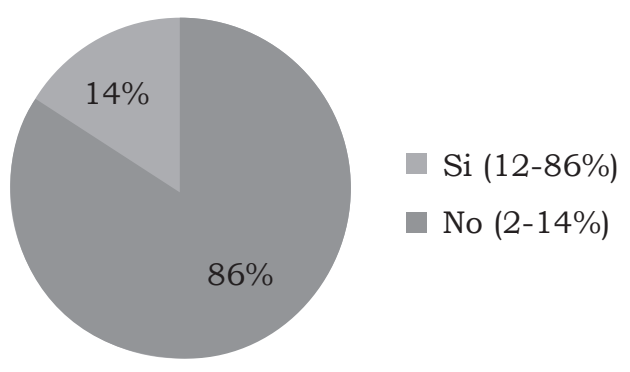

Finalmente, los magistrados encuestados manifiestan que se debe implementar una ley especial que regule expresamente la alienación parental, su concepto, las formas de manifestación, el abordaje psicológico y legal que deben realizar los miembros del equipo multidisciplinario, y las medidas de protección que deberán ser aplicadas por los operadores judiciales.

\section{CONCLUSIONES}

La alienación parental es una conducta obstruccionista y de manipulación realizada de manera reiterada e injustificada por el progenitor que tiene la tenencia. Su finalidad es perjudicar la relación personal, el contacto directo y la comunicación permanente del hijo con el otro progenitor a fin de que se manifieste en los procesos donde se determina la tenencia y el régimen de visitas.
La alienación parental está presente aproximadamente en el $70 \%$ de los procesos de tenencia y/o de régimen de visitas llevados en los juzgados de Familia de la Corte Superior de Justicia de Lima. Sin embargo, existe un vacío normativo sobre su regulación jurídica que impide que en los informes del equipo multidisciplinario, en el dictamen del fiscal de Familia y en las resoluciones judiciales se consigne expresamente la manifestación de este problema.

\section{RECOMENDACIONES}

Incorporar una ley especial que regule expresamente la alienación parental. En ella se puede establecer su concepto, las formas de manifestación, el abordaje psicológico y legal que deben aplicar los miembros del equipo multidisciplinario, las medidas de protección que deberán ser aplicadas por los operadores judiciales y las actuaciones procesales del juez especializado y del fiscal de Familia en estos casos.

Modificar los artículos $82^{\circ}$ y $91^{\circ}$ del Código de los Niños y Adolescentes para incorporar la alienación parental como causa de variación de la tenencia.

\section{FUENTES BIBLIOGRÁFICAS}

Aguilar Cuenca, J. (2006). Síndrome de alienación parental. Hijos manipulados por un cónyuge para odiar al otro. España: Editorial Almuzara, pp. 23. 
Aguilar Llanos, B. (2010). La Familia en el Código Civil Peruano. Lima: Ediciones Legales, pp. 306.

Aguilar Saldívar, A. (2008). El síndrome de alienación parental: implicancias en el binomio tenencia-régimen de visitas. En: JUS Doctrina y Práctica, (12), pp.169-174.

Álvarez Vélez, M. (1994). La protección de los derechos del niño. En el marco de las Naciones Unidas y en el derecho constitucional español. Madrid: UPCO, pp. 104.

Baratta, A. (2007). Democracia y derechos del niño. Justicia y derechos del niño (9), pp.1725. Recuperado de: http://www.unicef.org/ argentina/spanish/Justcia_y_derechos_9.pdf

Bautista Tomá, P. y Herrero Pons, J. (2008). Manual de derecho de familia. Lima: Ediciones Jurídicas.

Belluscio, A. (2013). Manual de derecho de familia. Buenos Aires: Abeledo Perrot, pp. 381-382.

Beloff, M. (2004). Un modelo para armar iy otro para desarmar!: Protección integral de derechos del niño vs. derechos en situación irregular. En: Los Derechos del Niño en el Sistema Interamericano. Buenos Aires: Editores del Puerto, pp.1-45.

Beltrán Pacheco, P. (2004). Dejad que mis hijos vengan a mí: El síndrome de alienación parental vs. la tenencia compartida. En: Cuadernos de Investigación y Jurisprudencia, (3), pp.89-96.

Bermúdez Tapia, M. (2009). Violencia familia: el síndrome de alienación parental. En: RAE Jurisprudencia, 1 (8), pp.49-63.

Bermúdez Tapia, M. (2012a). Síndrome de alienación parental, obstrucción de vínculo y padrectomía. Desarrollo procesal $\mathrm{y}$ jurisdiccional de conflictos en relaciones familiares de crisis. Revista Jurídica del Perú, (131), pp.242-273.

Berrocal Lanzarot, A. (2012b). El síndrome de alienación parental. Casuística comparada. En: Revista Jurídica del Perú, (132), pp.223-250.

Bolaños Cartujo, I. (2000). Estudio descriptivo del Síndrome de Alienación Parental en procesos de separación y divorcio. Diseño y aplicación de un programa piloto de mediación familiar. Memoria para optar el grado de doctor en Psicología. Facultad de Psicología, Universidad Autónoma de Barcelona, España.

Bolaños, I. (2002). El síndrome de alienación parental. Descripción y abordajes psicolegales. En: Psicología Clínica, Legal y Forense, 2 (3), pp. 25-45.

Borda, G. (2002). Manual de derecho de familia. Buenos Aires: Abeledo Perrot.

Bossert, G. y Zannoni, E. (2004). Manual de derecho de familia. Buenos Aires: Editorial Astrea.

Campana Valderrama, M. (2006). Síndrome de Alienación Parental en los procesos de tenencia y régimen de visitas. En: Jurídica: Suplemento de Análisis Legal del diario oficial El Peruano, 3 (116), pp. 4-5.

Cardona Llorens, J. (2012). La Convención sobre los Derechos del Niño: significado, alcance y nuevos retos. En: Educatio Siglo XXI, 30 (2), pp.47-67. Recuperado de: http://revistas.um.es/educatio/article/ view/153681/140721

Chunga Lamonja, F., Chunga Chávez, C. y Chunga Chávez, L. (2012). Los derechos de los niños, niñas y adolescentes y su protección en los derechos humanos. Lima: Grijley, pp. 399.

Cillero Bruñol, M. (1998). El interés superior del niño en el marco de la Convención Internacional sobre los Derechos del Niño. García Méndez, E. y Beloff, M. (comps.). En: Infancia, Ley y Democracia en América Latina. Santa Fe de Bogotá: Temis/Depalma, pp.79-99.

Comité de los Derechos del Niño. (2009). Observación general: el derecho del niño a ser escuchado, (12). Recuperado de: http:// www2.ohchr.org/english/ bodies/crc/docs/ AdvanceVersions/CRC-C-GC-12_sp.doc

Comité de los Derechos del Niño. (2013). Observación general: sobre el derecho del niño a que su interés superior sea una consideración primordial, (14). Recuperado de: http://tbinternet.ohchr.org/Treaties/CRC/ Shared\%20 Documents/1_Global/CRC_C_ GC_14_7202_S.doc 
Cornejo Chávez, H. (1999). Derecho Familiar Peruano. Lima: Gaceta Jurídica, pp. 517.

Corte Interamericana de Derechos Humanos. (2002). Opinión Consultiva OC-17/2002. Recuperado de: http://www.corteidh.or.cr/ docs/opiniones/seriea_17_esp.pdf

Congreso de la República del Perú. (2013). Dictamen de la Comisión de la mujer y familia del Congreso de la República recaído en los proyectos de ley N. ${ }^{\circ} 495 / 2011-\mathrm{CR}$, 661/2011-CR, 727/2011-CR, 944/2011-PE, 962/2011-CR, 1590/2012-CR, 1737/2012-CR, 1791/2012-CR, 1878/2012-CR， 1886/2012CR, 1915/2012-CR, 1916/2012-CR, $2162 / 2012-C R, 2221 / 2012-C R$ y $2229 / 2012-$ CR para la aprobación del proyecto del Nuevo Código de los Niños y Adolescentes. Recuperado de: http://www.congreso.gob.pe/ index.php? $\mathrm{K}=55$

Díaz Usandivaras, C. (2002). El Síndrome de Alienación Parental (SAP): Una forma sutil de violencia después de la separación o el divorcio. En: Derecho de Familia: Revista Interdisciplinaria de Doctrina y Jurisprudencia, (24), pp.127-142.

Gallegos Canales, Y. y Jara Quispe, R. (2008). Manual de derecho de familia. Lima: Jurista Editores.

Fernández, W. (2015). La influencia de la alienación parental en el régimen de visitas. Memoria para optar el título profesional de abogado, Facultad de Derecho. Lima: Universidad de San Martín de Porres, p. 9.

Garay Molina, A. (2009). Custodia de los hijos cuando se da fin al matrimonio. Tenencia unilateral o tenencia compartida (coparentalidad). Lima: Girjley.

García Méndez, E. (2004). Legislaciones infanto-juveniles en América Latina: modelos y tendencias. En: Infancia. De los Derechos y de la Justicia. Buenos Aires: Editores del Puerto, pp.1-16.

Giménez de Allen, M. (2010). El derecho del niño(a) a ser oído y el deber del juez de escuchar su opinión de manera adecuada. En: El Interés Superior del Niño, Tomo II. Asunción: Corte Suprema de Justicia/División de Investigación, Legislación y Publicaciones, pp.95-103.
Gimeno, J. y Orti, M. (2011). La prueba pericial en los procesos familiares. El SATAF (Servicio de Asesoramiento Técnico en el Ámbito de Familia). Carlos Villagrasa Alcaide (comp.), En: Derecho de Familia. Barcelona: Editorial Bosh, pp.657-677.

González Martín, N. (2011). Convivencia paterno-materno filial en el panorama internacional: un acercamiento en torno a la sustracción de menores, alienación parental y mediación familiar internacional. En: Alienación Parental. México D.F.: Comisión Nacional de los Derechos Humanos. Recuperado de: http://www.corteidh.or.cr/ tablas/r28806.pdf. Pp.9-52.

Hinostroza Mínguez, A. (2012). Procesos judiciales derivados del derecho de familia. Lima: Iustitia/Grijley.

Instituto Nacional de Estadística e Informática - INEI. (2013a). En: Perú: nacimientos, defunciones, matrimonios y divorcios, 2011. Recuperado de: http://www.inei.gob.pe/media/ MenuRecursivo/publicaciones_digitales/Est/ Lib1081/libro.pdf

Instituto Nacional de Estadística e Informática - INEI. (2013b). Perú: nacimientos, defunciones, matrimonios y divorcios, 2012. Recuperado de: http://www.inei.gob.pe/media/ MenuRecursivo/publicaciones_digitales/Est/ Lib1100/libro.pdf

Jara, R. y Gallegos, Y. (2011). Manual de derecho de familia. Lima: Jurista Editores, p 438 .

Kemelmajer de Carlucci, A. (2012). La guarda compartida. Una visión comparativa. En: Revista de Derecho Privado, edición especial, pp.231-286. Recuperado de: http://www. juridicas.unam.mx/publica/librev/rev/derpriv/ cont/23/dtr/dtr10.pdf

Laino Pereyra, S. (2012). Autonomía progresiva de la voluntad. En: Manual para la defensa jurídica de los derechos humanos de la infancia. Montevideo: Unicef, pp.17-37.

Mejía Salas, P. (2002). La Patria Potestad. Lima: LEJ.

Mejía Salas, P. y Ureta Guerra, M. (2005). Tenencia y régimen de visitas. Lima: LEJ pp. 73 y 74. 
Mejía Salas, P. (2013). El régimen de visitas. En: Revista internacional Supra Iuris: Familiae, (1), pp.67-73.

Méndez Costa, M. y D' Antonio, D. (2001). Derecho de familia, Tomo III. Buenos Aires: Rubinzal-Culzoni Editores, pp. 496.

O’Donnell, D. (1990). La Convención sobre los Derechos del Niño: estructura y contenido. En: Boletín del Instituto Interamericano del Niño, (230), p. 11 y ss.

Peralta Andía, J. (2008). Derecho de familia en el Código Civil. Lima: Editorial Idemsa.

Pérez Duarte y N., A. (1990). Derecho de familia. México D.F.: Universidad Nacional Autónoma de México.

Plácido Vilcachagua, A. (2001). Manual de derecho de familia. Lima: Gaceta Jurídica, pp. 19-20.

Plácido Vilcachagua, A. (2011). La valoración judicial de la opinión del niño alienado conforme con la Convención sobre los Derechos del Niño. En: Revista Jurídica del Perú, (129), pp. 17-23.

Rentería Durand, M. (2012). Las medidas cautelares en el derecho de familia. Lima: LEJ.

Rivero Hernández, F. (2000). El interés del menor. Madrid: Dykinson.
Rodríguez Quintero, L. (2011). Alienación parental y derechos humanos en el marco jurídico nacional. Algunas consideraciones. En: Alienación Parental. México D.F.: Comisión Nacional de los Derechos Humanos. Recuperado de: http://www.corteidh.or.cr/ tablas/r28806.pdf. Pp.53-93.

San Segundo Manuel, T. (2011). Maltrato y separación: repercusiones en los hijos. Carlos Villagrasa Alcaide (comp). En: Derecho de Familia. Barcelona: Editorial Bosh, pp.541-582.

Torrealba Jenkins, A. (2011). El Síndrome de Alienación Parental en la legislación de familia. Memoria para optar el grado de magíster en Derecho. Facultad de Derecho, Universidad de Chile, Chile, pp. 28 y 31.

Varsi Rospigliosi, E. (2004). Divorcio, filiación y patria potestad. Lima, Perú: Grijley, pp. 240.

Varsi Rospigliosi, E. (2012a). Tratado de derecho de familia, Tomo III. Lima: Gaceta Jurídica.

Varsi Rospigliosi, E. y Paz Sáenz, M. (2012b). Casuística del Síndrome de Alienación Parental. Diálogo con la Jurisprudencia, (161), pp. 105-109 y 384 .

Vásquez García, Y. (1998). Derecho de familia. Tomo II. Lima: Editorial Huallaga. 